\title{
Vaginal McCall culdoplasty versus laparoscopic uterosacral plication to prophylactically address vaginal vault prolapse
}

\author{
Kathy Niblock ${ }^{1 *}$, Emily Bailie², Geoff McCracken ${ }^{1}$ and Keith Johnston ${ }^{2}$
}

\begin{abstract}
Background: Studies have shown that vaginal vault prolapse can affect up to $43 \%$ of women following hysterectomy for pelvic organ prolapse. Many techniques have been described to prevent and treat vaginal vault prolapse. The primary objective of our study was to compare McCall's culdoplasty (when performed along side vaginal hysterectomy) with laparoscopic uterosacral plication (when performed along side total laparoscopic hysterectomy) for prevention of vaginal vault prolapse. Secondary outcomes included inpatient stay and perioperative complications.

A retrospective comparison study comparing 73 patients who underwent 'laparoscopic hysterectomy and uterosacral plication' against 70 patients who underwent 'vaginal hysterectomy and McCall culdoplasty'. All operations were carried out by two trained surgeons.

Results: There was no significant difference between BMI or parity. There were statistically significantly more patients presenting with post hysterectomy vault prolapse (PHVP) in the group of patients who had undergone uterosacral plication (12 out of 73) compared with McCalls culdoplasty (0 out of 70) $P=0.000394$. Inpatient stay in the uterosacral plication group was significantly shorter mean 1.8 compared to 3.6 for McCall group ( $P$-Value is $<0.00001)$. There was no significance in the perioperative complications between both groups $(P=0.41)$.
\end{abstract}

Conclusions: McCalls is a superior operation to prevent PHVP compared to uterosacral plication with no difference in terms of perioperative complications.

Keywords: Vault prolapse, McCall culdoplasty, Uterosacral plication

\section{Background}

The International Continence Society defines posthysterectomy vault prolapse (PHVP) as descent of the vaginal cuff scar below a point that is $2 \mathrm{~cm}$ less than the total vaginal length above the plane of the hymen [1]. The incidence of PHVP has been reported to affect up to $43 \%$ of hysterectomies. The risk of prolapse following hysterectomy is 5.5 times more common in women

\footnotetext{
* Correspondence: kathyniblock@doctors.org.uk

${ }^{1}$ Craigavon Area Hospital, 68 Lurgan Rd, Portadown, Craigavon, BT63 5QQ,

Northern Ireland

Full list of author information is available at the end of the article
}

whose initial hysterectomy was for pelvic organ prolapse as opposed to other reasons [1].

Preventative techniques can be used at the time of a hysterectomy to prevent PHVP. McCall culdoplasty and sacrospinous fixation can be carried out at vaginal hysterectomy [2]. Suturing the cardinal and uterosacral ligaments to the vaginal cuff at the time of abdominal or laparoscopic hysterectomy is effective in preventing post-hysterectomy vaginal prolapse [3].

Recommended management for PHVP can be largely divided into surgical and non-surgical. Methods of treatment offered depend on severity of prolapse but also takes into consideration patient wishes and expectations 
and suitability for surgery. Conservative management includes weight loss, treatment of constipation and avoidance of heavy lifting. Patients may also avail of physiotherapy and ring pessaries [4].

Techniques available to manage PHVP aim to ultimately suspend the vaginal vault. Approaches include vaginal, e.g. uterosacral ligament suspension, sacrospinous ligament fixation, open procedures and more recently laparoscopic, e.g. sacrocolpopexy and uterosacral plication $[2,5]$. The decision-making process for managing these patients is similar to that of any prolapse, namely the response to conservative management, the effect on the quality of life and fitness for surgery [1].

\section{Methods}

Patients were identified who underwent 'laparoscopic hysterectomy with uterosacral plication' and 'vaginal hysterectomy with McCall culdoplasty' for pelvic organ prolapse performed by two consultant gynaecologists in Northern Ireland between January 2008 and January 2014. One surgeon performed each of the described procedures.

All patients had presented with subjective symptoms of pelvic organ prolapse, and objectively, this was confirmed on objective Pelvic Organ Prolapse Quantification (POP-Q) examination.

The technique used for vaginal hysterectomy and McCall culdoplasty is described by Raymond Lee of The Mayo Clinic [6]. Following vaginal hysterectomy, one to two internal McCall sutures are placed using a zero monofilament absorbable suture. Each McCall suture is placed deeply into the left pararectal fascia then across the front of the sigmoid colon and deep into the right pararectal fascia. An external McCall suture is subsequently placed, more cephalad to the internal McCall suture. A 1-0 delayed absorbable suture is passed through the posterior vaginal wall incorporating the peritoneum. The same suture is then placed deep through the left pararectal fascia, across the sigmoid colon and deep through the right pararectal fascia. The same external McCall suture is then placed back through the vaginal wall. Depending on anterior and posterior compartment prolapse, the patients may have also undergone an anterior and/or posterior colporrhaphy. All patients underwent routine cystoscopy with indigo carmine.

In the patients undergoing uterosacral plication, following total laparoscopic hysterectomy, the ureters were re-identified. A non-absorbable, zero monofilament suture was used to place three helical sutures full thickness in each uterosacral ligament, beginning in the distal third of the ligament and incorporating the posterior vagina. The ends of the suture were tied with an extra- corporeal knot-tying technique, thus shortening the uterosacral ligaments.

Both groups of patients had their charts reviewed retrospectively and were followed up on a regional electronic care record to see if they attended anywhere in the province for subsequent pelvic organ prolapse repairs.

A total of 143 patients were identified including 73 who had undergone total laparoscopic hysterectomy and uterosacral plication and 70 who had vaginal hysterectomy and McCall culdoplasty.

Mean follow-up was 36 months (range 5-84) in the uterosacral plication group and 41 months (range 5-71) in the McCall culdoplasty group.

The notes were reviewed for parity, age, BMI, indication for surgery, the surgical procedure performed, perioperative or post-operative complications, duration of inpatient stay and findings at their 6-month postoperative review where a POP-Q was performed along with any subsequent attendances.

\section{Results \\ Demographics}

The demographics for the uterosacral plication and the McCall culdoplasty groups are summarized in Table 1.

The mean parity and BMI in both groups were comparable with $P$ values of 0.21 and 0.09 respectively. ( $P$ values were calculated using Student's $t$ test.) The mean parity in patients who underwent uterosacral plication was 3.1 compared with 3.0 in the McCall culdoplasty group. The mean BMI in patients who underwent uterosacral plication was 26.5 compared with 28.0 in the McCall culdoplasty group.

There was a statistical significance in the age difference of both groups of patients $(P=0.00024)$. The McCall patient group had a mean age of 59 (range 3782) while the patients undergoing uterosacral plication had a mean age of 52.3 (range $31-72$ )

\section{Inpatient stay}

The mean inpatient stay for patients in the laparoscopic hysterectomy and uterosacral plication group was 1.8 days (range 1-5 days). The mean inpatient stay for patients in the vaginal hysterectomy and McCall culdoplasty group was 3.6 days (range 2-7 days). There was a statistically significant difference in the duration of

Table 1 Demographics for the uterosacral plication and the McCall culdoplasty patient groups

\begin{tabular}{llll}
\hline & USP & McCall's & $P$ value \\
\hline Mean age (range) & $52.3(31-72)$ & $59(37-82)$ & 0.00024 \\
Mean parity (range) & $3.1(1-6)$ & $3.0(1-8)$ & 0.21 \\
Mean BMI (range) & $26.5(16.7-41)$ & $28.0(20-36)$ & 0.09 \\
\hline
\end{tabular}


hospital stay in the two groups; $P$ value is $<0.00001$ using Student's $t$ test.

\section{Indication}

In both groups, the indication for surgery in all patients was vaginal prolapse. In patients who had objective associated anterior or posterior vaginal wall prolapse, additional procedures were carried out to address this. These procedures included anterior colporrhaphy, posterior colporrhaphy and laparoscopic paravaginal repair. Laparoscopic paravaginal repair is a procedure using a delayed absorbable suture to attach the lateral aspects of the front vaginal wall back to the arcus tendinous. It is a procedure used to address anterior lateral vaginal wall defects.

In the patients undergoing vaginal hysterectomy and McCall culdoplasty, four patients also complained of heavy menstrual bleeding. In the patients undergoing laparoscopic hysterectomy and uterosacral ligament plication, three patients also complained of heavy menstrual bleeding.

\section{Procedure}

Details of the procedures performed for utero-vaginal prolapse are summarized in Tables 2 and 3.

\section{Complications}

Seventeen patients in total had reported complications. This included ten patients in the McCall culdoplasty group and seven patients in the uterosacral plication group. See Tables 4 and 5 for details.

In the patients undergoing laparoscopic hysterectomy and uterosacral plication, three patients require antibiotics for port site wound infections. Two patients had post-operative urinary retention, one that was managed conservatively and one that required release of sutures at the bladder neck following paravaginal repair. One patient re-attended with port

Table 2 Details of laparoscopic procedure

\begin{tabular}{ll}
\hline Procedure & $\begin{array}{l}\text { Number of } \\
\text { patients }\end{array}$ \\
\hline $\begin{array}{l}\text { Total laparoscopic hysterectomy ( } \pm \mathrm{BSO} \text { ) and uterosacral } \\
\text { plication }\end{array}$ & 32 \\
$\begin{array}{l}\text { Total laparoscopic hysterectomy ( } \pm \mathrm{BSO} \text { ) and uterosacral } \\
\text { plication and posterior colporrhaphy }\end{array}$ & 21 \\
$\begin{array}{l}\text { Total laparoscopic hysterectomy ( } \pm \mathrm{BSO} \text { ) and uterosacral } \\
\text { plication and laparoscopic paravaginal repair }\end{array}$ & 9 \\
$\begin{array}{l}\text { Total laparoscopic hysterectomy }( \pm \mathrm{BSO}) \text { and uterosacral } \\
\text { plication and posterior colporrhaphy and laparoscopic } \\
\text { paravaginal repair }\end{array}$ & 5 \\
$\begin{array}{l}\text { Total laparoscopic hysterectomy ( } \pm \mathrm{BSO} \text { ) and uterosacral } \\
\text { plication and anterior colporrhaphy }\end{array}$ & 5 \\
$\begin{array}{l}\text { Total laparoscopic hysterectomy }( \pm \mathrm{BSO}) \text { and uterosacral } \\
\text { plication and anterior colporrhaphy and posterior } \\
\text { colporrhaphy }\end{array}$ & 1 \\
\begin{tabular}{l} 
Total \\
\hline
\end{tabular} & 73 \\
\hline
\end{tabular}

Table 3 Details of vaginal procedure

\begin{tabular}{ll}
\hline Procedure & $\begin{array}{l}\text { Number of } \\
\text { patients }\end{array}$ \\
\hline $\begin{array}{l}\text { Vaginal hysterectomy }( \pm \mathrm{BSO}) \text { and McCall culdoplasty and } \\
\text { anterior colporrhaphy and posterior colporrhaphy }\end{array}$ & 60 \\
$\begin{array}{l}\text { Vaginal hysterectomy }( \pm \mathrm{BSO}) \text { and McCall culdoplasty and } \\
\text { anterior colporrhaphy }\end{array}$ & 4 \\
Vaginal hysterectomy $( \pm \mathrm{BSO})$ and McCall culdoplasty & 3 \\
$\begin{array}{l}\text { Vaginal hysterectomy }( \pm \mathrm{BSO}) \text { and McCall culdoplasty and } \\
\text { posterior colporrhaphy }\end{array}$ & 3 \\
Total & 70 \\
\hline
\end{tabular}

site herniation, 2 weeks after surgery, that required surgical management. One patient had a vault haematoma, which was managed conservatively with antibiotics.

One patient undergoing McCall culdoplasty required intraoperative release of the McCall due to evidence of ureteric obstruction at routine cystoscopy performed during the procedure. Six patients in the McCall culdoplasty group had post-operative urinary retention. All of these were successfully managed conservatively with a period of intermittent self-catheterization. Two patients returned to theatre for a laparotomy for post-operative intra-abdominal bleeding in the first $24 \mathrm{~h}$ postoperatively. One patient required a subsequent Blair Bell (Fenton's) procedure for post-operative dyspareunia which failed to respond to conservative measures.

\section{Post-operative findings}

Mean follow-up time was 36 months in the uterosacral plication group and 41 months in the McCall culdoplasty group. All patients were assessed 6 months post-

Table 4 Complications in uterosacral plication patient group

\begin{tabular}{|c|c|c|}
\hline Complication & Operation & Management \\
\hline Wound infection & $\begin{array}{l}\text { Laparoscopic hysterectomy and } \\
\text { uterosacral plication and } \\
\text { posterior colporrhaphy }\end{array}$ & Oral antibiotics \\
\hline Wound infection & $\begin{array}{l}\text { Laparoscopic hysterectomy } \\
\text { and uterosacral plication }\end{array}$ & Oral antibiotics \\
\hline Wound infection & $\begin{array}{l}\text { Laparoscopic hysterectomy } \\
\text { and uterosacral plication }\end{array}$ & IV antibiotics \\
\hline Urinary retention & $\begin{array}{l}\text { Laparoscopic hysterectomy } \\
\text { and uterosacral plication } \\
\text { and posterior colporrhaphy } \\
\text { and paravaginal repair }\end{array}$ & $\begin{array}{l}\text { Conservative } \\
\text {-ISC }\end{array}$ \\
\hline Urinary retention & $\begin{array}{l}\text { Laparoscopic hysterectomy } \\
\text { and uterosacral plication } \\
\text { and paravaginal repair }\end{array}$ & $\begin{array}{l}\text { Revision of } \\
\text { sutures at } \\
\text { bladder neck } \\
\text { following } \\
\text { paravaginal } \\
\text { repair }\end{array}$ \\
\hline Vault haematoma & $\begin{array}{l}\text { Laparoscopic hysterectomy } \\
\text { and uterosacral plication }\end{array}$ & IV antibiotics \\
\hline Port site herniation & $\begin{array}{l}\text { Laparoscopic hysterectomy } \\
\text { and uterosacral plication }\end{array}$ & $\begin{array}{l}\text { Surgically } \\
\text { managed }\end{array}$ \\
\hline
\end{tabular}


Table 5 Complications in the McCall culdoplasty patient group

\begin{tabular}{|c|c|c|}
\hline Complication & Operation & Management \\
\hline Urinary retention & $\begin{array}{l}\text { Vaginal hysterectomy and McCall culdoplasty and anterior colporrhaphy and } \\
\text { posterior colporrhaphy }\end{array}$ & Conservative-ISC \\
\hline Urinary retention & $\begin{array}{l}\text { Vaginal hysterectomy and McCall culdoplasty and anterior colporrhaphy and } \\
\text { posterior colporrhaphy }\end{array}$ & Conservative-ISC \\
\hline Urinary retention & $\begin{array}{l}\text { Vaginal hysterectomy and McCall culdoplasty and anterior colporrhaphy and } \\
\text { posterior colporrhaphy }\end{array}$ & Conservative-ISC \\
\hline Urinary retention & $\begin{array}{l}\text { Vaginal hysterectomy and McCall culdoplasty and anterior colporrhaphy and } \\
\text { posterior colporrhaphy }\end{array}$ & Conservative-ISC \\
\hline Urinary retention & $\begin{array}{l}\text { Vaginal hysterectomy and McCall culdoplasty and anterior colporrhaphy and } \\
\text { posterior colporrhaphy }\end{array}$ & Conservative-ISC \\
\hline Urinary retention & $\begin{array}{l}\text { Vaginal hysterectomy and McCall culdoplasty and anterior colporrhaphy and } \\
\text { posterior colporrhaphy }\end{array}$ & Conservative-ISC \\
\hline Post-operative bleeding & $\begin{array}{l}\text { Vaginal hysterectomy and McCall culdoplasty and anterior colporrhaphy and } \\
\text { posterior colporrhaphy }\end{array}$ & Return to theatre; laparotomy \\
\hline Post-operative bleeding & $\begin{array}{l}\text { Vaginal hysterectomy and McCall culdoplasty and anterior colporrhaphy and } \\
\text { posterior colporrhaphy }\end{array}$ & Return to theatre; laparotomy \\
\hline Post-operative dyspareunia & $\begin{array}{l}\text { Vaginal hysterectomy and McCall culdoplasty and anterior colporrhaphy and } \\
\text { posterior colporrhaphy }\end{array}$ & Blair Bell/Fenton's procedure \\
\hline Ureteric obstruction seen at cystoscopy & $\begin{array}{l}\text { Vaginal hysterectomy and McCall culdoplasty and anterior colporrhaphy and } \\
\text { posterior colporrhaphy }\end{array}$ & $\begin{array}{l}\text { Release of McCall culdoplasty } \\
\text { intraoperatively }\end{array}$ \\
\hline
\end{tabular}

There was no significance in the perioperative complications between both groups $(P=0.41)$

operatively where subjective and objective (POP-Q) assessments of subsequent prolapse symptoms were ascertained by the same two surgeons.

\section{Uterosacral plication}

In the uterosacral plication group, 53 out of 73 (72.6\%) patients had no further pelvic organ prolapse.

Twelve patients (16.4\%) have had PHVP. Eight patients have opted for surgical repair. Of the eight patients undergoing surgical repair for PHVP, four patients had a subsequent laparoscopic sacrocolpopexy, one patient had a laparoscopic sacrocolpopexy that was converted to an open procedure intraoperatively due to dense adhesions, one patient had a sacrospinous ligament fixation and two patients had repeat uterosacral ligament plications performed. Four patients opted for insertion of vaginal pessary. See Table 6.

Seven patients (9.5\%) have had de novo anterior compartment prolapse. Four patients (5.4\%) had recurrence of anterior wall prolapse. Seven patients opted for surgical repair, two patients opted for vaginal pessary insertion and two patients have chosen conservative management. See Table 7.

\section{McCall culdoplasty}

In the McCall culdoplasty group, there have been no patients with PHVP. Four patients have represented with

Table 6 Vaginal vault prolapse following laparoscopic hysterectomy and uterosacral plication

\begin{tabular}{|c|c|}
\hline Original operation & Repair of PHVP \\
\hline Laparoscopic hysterectomy and uterosacral plication & Laparoscopic sacrocolpopexy \\
\hline Laparoscopic hysterectomy and uterosacral plication and paravaginal repair & Laparoscopic sacrocolpopexy \\
\hline Laparoscopic hysterectomy and uterosacral plication & Laparoscopic sacrocolpopexy \\
\hline Laparoscopic hysterectomy and uterosacral plication and paravaginal repair & Laparoscopic sacrocolpopexy \\
\hline Laparoscopic hysterectomy and uterosacral plication and paravaginal repair & $\begin{array}{l}\text { Laparoscopic sacrocolpopexy converted to open } \\
\text { sacrospinous ligament fixation }\end{array}$ \\
\hline Laparoscopic hysterectomy and uterosacral plication & Vaginal sacrospinous ligament fixation \\
\hline Laparoscopic hysterectomy and uterosacral plication & Laparoscopic uterosacral ligament plication \\
\hline Laparoscopic hysterectomy and uterosacral plication and paravaginal repair & Laparoscopic uterosacral ligament plication \\
\hline Laparoscopic hysterectomy and uterosacral plication and anterior colporrhaphy & Pessary \\
\hline Laparoscopic hysterectomy and uterosacral plication & Pessary \\
\hline Laparoscopic hysterectomy and uterosacral plication and posterior colporrhaphy & Pessary \\
\hline Laparoscopic hysterectomy and uterosacral plication & Pessary \\
\hline
\end{tabular}


Table 7 Anterior compartment prolapse following laparoscopic hysterectomy and uterosacral plication

\begin{tabular}{ll}
\hline Original operation & Management \\
\hline Laparoscopic hysterectomy and uterosacral & Anterior colporrhaphy \\
plication and posterior colporrhaphy & \\
Laparoscopic hysterectomy and uterosacral & Anterior colporrhaphy \\
plication & \\
Laparoscopic hysterectomy and uterosacral & Anterior colporrhaphy \\
plication & \\
Laparoscopic hysterectomy and uterosacral & Anterior colporrhaphy \\
plication and anterior colporrhaphy & \\
Laparoscopic hysterectomy and uterosacral & Laparoscopic paravaginal \\
plication and paravaginal repair & repair \\
Laparoscopic hysterectomy and uterosacral & Laparoscopic paravaginal \\
plication & repair \\
Laparoscopic hysterectomy and uterosacral & Vaginal Elevate mesh \\
plication and anterior colporrhaphy & \\
Laparoscopic hysterectomy and uterosacral & Conservative-no treatment \\
plication & \\
Laparoscopic hysterectomy and uterosacral & Conservative-no treatment \\
plication and paravaginal repair & \\
Laparoscopic hysterectomy and uterosacral & Pessary \\
plication & \\
Laparoscopic hysterectomy and uterosacral & Pessary \\
plication &
\end{tabular}

Four patients (5.4\%) have had de novo posterior compartment prolapse; three have opted for surgical repair

posterior compartment prolapse (Table 8), and two patients have represented with anterior compartment prolapse. Two of these patients have required surgical management for their symptoms. One patient underwent a subsequent anterior colporrhaphy, and one patient has undergone a subsequent posterior colporrhaphy. See Tables 9 and 10.

\section{Discussion and conclusions}

The aetiology of PHVP is multifactorial; however, damage to the level one supports of the vagina during hysterectomy are thought to be a major contributing factor. The risk of this is thought to be greatest when the hysterectomy is performed for the indication of pelvic organ prolapse [7].

Table 8 Posterior compartment prolapse following laparoscopic hysterectomy and uterosacral plication

\begin{tabular}{ll}
\hline Original operation & Management \\
\hline $\begin{array}{l}\text { Laparoscopic hysterectomy and uterosacral } \\
\text { plication }\end{array}$ & Posterior colporrhaphy \\
$\begin{array}{l}\text { Laparoscopic hysterectomy and uterosacral } \\
\text { plication and paravaginal repair }\end{array}$ & Posterior colporrhaphy \\
$\begin{array}{l}\text { Laparoscopic hysterectomy and uterosacral } \\
\text { plication }\end{array}$ & Posterior colporrhaphy \\
$\begin{array}{l}\text { Laparoscopic hysterectomy and uterosacral } \\
\text { plication and anterior colporrhaphy }\end{array}$ & $\begin{array}{l}\text { Conservative-no } \\
\text { treatment }\end{array}$ \\
\hline
\end{tabular}

Table 9 Anterior compartment prolapse following vaginal hysterectomy and McCall culdoplasty

\begin{tabular}{ll}
\hline Original operation & Management \\
\hline $\begin{array}{l}\text { Vaginal hysterectomy and McCall culdoplasty and } \\
\text { anterior colporrhaphy and posterior colporrhaphy }\end{array}$ & $\begin{array}{l}\text { Anterior } \\
\text { colporrhaphy }\end{array}$ \\
$\begin{array}{l}\text { Vaginal hysterectomy and McCall culdoplasty and } \\
\text { anterior colporrhaphy and posterior colporrhaphy }\end{array}$ & Conservative \\
\hline
\end{tabular}

There are very few studies comparing vaginal McCall culdoplasty to laparoscopic uterosacral plication for prevention of subsequent prolapse.

In 1957, McCall described attaching the uterosacral ligaments to the posterior vaginal cuff and the cul de sac peritoneum in order to close off the cul de sac and prevent subsequent prolapse [8].

Uterosacral plication does not obliterate the cul de sac. It involves placing sutures distally on the uterosacral ligaments and tying them in the midline under tension away from their attachment into the vagina. The support this provides for the vagina has so far been unclear [9]. One of the theoretical advantages of laparoscopic over vaginal technique is the ability to identify the ureters, thus reducing the chance of inadvertent ureteric injury. Our study shows that in trained hands and with the prudent employment of indigo carmine and routine cystoscopy, the rate of ureteric injury is not significantly higher in the vaginal McCall group.

This study has retrospectively evaluated the McCall culdoplasty and the laparoscopic uterosacral plication when performed alongside hysterectomies in order to prevent PHVP. It has found them comparable in terms of complications encountered. Laparoscopic uterosacral plication has a statistically significant shorter hospital admission; however, McCall culdoplasty has proven to be superior to laparoscopic uterosacral plication in terms of patients representing with subsequent pelvic organ prolapse.

While both groups had a low rate of PHVP, in this study, McCall culdoplasty was a more successful operation compared to uterosacral plication with no difference in terms of perioperative complications.

Table 10 Posterior compartment prolapse following vaginal hysterectomy and McCall culdoplasty

\begin{tabular}{ll}
\hline Original operation & Management \\
\hline $\begin{array}{l}\text { Vaginal hysterectomy and McCall culdoplasty and } \\
\text { anterior colporrhaphy and posterior colporrhaphy }\end{array}$ & $\begin{array}{l}\text { Posterior } \\
\text { colporrhaphy } \\
\text { Vaginal hysterectomy and McCall culdoplasty and } \\
\text { anterior colporrhaphy and posterior colporrhaphy }\end{array}$ \\
$\begin{array}{l}\text { Vaginal hysterectomy and McCall culdoplasty and } \\
\text { anterior colporrhaphy and posterior colporrhaphy }\end{array}$ & Conservative \\
$\begin{array}{l}\text { Vaginal hysterectomy and McCall culdoplasty and } \\
\text { anterior colporrhaphy and posterior colporrhaphy }\end{array}$ & Conservative \\
\hline
\end{tabular}




\section{Abbreviations}

BMI: Body mass index; BSO: Bilateral salpingo-oophorectomy;

ISC: Intermittent self-catheterization; PHVP: Post-hysterectomy vault prolapse; POP-Q: Pelvic Organ Prolapse Quantification

\section{Authors' contributions}

KN handled project development, data collecting and manuscript writing. EB handled data collecting and manuscript writing. GMC and KJ handled project development. All authors read and approved the final manuscript.

\section{Competing interests}

The authors declare that they have no competing interests.

\section{Ethics approval and consent to participate}

All procedures performed in the studies involving human participants were in accordance with the ethical standards of the institutional and/or nationa research committee and with the 1964 Declaration of Helsinki and its later amendments or comparable ethical standards. Informed consent was obtained from all individual participants included in the study.

\section{Author details}

'Craigavon Area Hospital, 68 Lurgan Rd, Portadown, Craigavon, BT63 5QQ, Northern Ireland. ${ }^{2}$ Antrim Area Hospital, 45 Bush Rd, Antrim BT41 2RL, Northern Ireland.

Received: 13 February 2017 Accepted: 24 March 2017

Published online: 12 April 2017

\section{References}

1. RCOG and BSUG joint guideline 2015. Green top guideline no 46-post hysterectomy vaginal vault prolapse, published 24/07/2015. https://www. rcog.org.uk/globalassets/documents/guidelines/gtg-46.pdf

2. NICE. Sacrocolpopexy using mesh for vaginal vault prolapse repair-NICE interventional procedure guideline IPG283 January 2009. https://www.nice. org.uk/guidance/ipg283/chapter/1-Guidance

3. Reda A, Sayed AT (2005) Post-hysterectomy vaginal vault prolapse. TOG 7:89-97

4. Azubuike U, Farag KA (2009) Vaginal vault prolapse. Int Obstet Gynecol 2009:275621

5. Chene G (2007) Anatomical and functional results of McCall culdoplasty in the prevention of enteroceles and vault prolapse after vaginal hysterectomy. Int Urogynaecol J 19:1007-1011

6. Lee R (2003) Vaginal hysterectomy with repair of enterocele, cystocele and rectocele. Clin Obstet Gynecol 36(4):967-975

7. Altman D, Falconer C, Cnattingius S, Granath F (2008) Pelvic organ prolapse surgery following prolapse for benign indications. Am J Obstet Gynecol 198(5):572

8. AAGL Advancing Minimally Invasive Gynecology Worldwide (2014) AAGL practice guidelines on the prevention of apical prolapse at the time of benign hysterectomy. J Minim Invasive Gynecol 21(5):715-722

9. O'Donovan P, Downes E (2002) Advances in gynaecological surgery, 1st edn. Greenwich Medical Media, London, pp 82-83, Chapter 7. Vault prolapse can it be prevented

\section{Submit your manuscript to a SpringerOpen ${ }^{\circ}$ journal and benefit from:}

- Convenient online submission

- Rigorous peer review

- Immediate publication on acceptance

- Open access: articles freely available online

- High visibility within the field

- Retaining the copyright to your article 